\section{Perception of Brazilian adolescents about cancer prevention}

\author{
Eduardo Blanco Cardoso* \\ School of Education, University of São Paulo (USP), Brazil
}

\section{Abstract}

Cancer, as a disease, has found a place in the social imaginary. Individuals construct ideas based on pre-established discourses-be they medical, media, or popular-which often hinder its prevention. Educational interventions have tended to focus on spreading information about the disease, ignoring its social connotations. The objective of the present study is to investigate the concept of cancer prevention in 980 adolescents, aged between 12 and 18 years, attending primary and secondary school in three public schools and one private school in the metropolitan region of São Paulo and the municipality of Dom Viçoso, Minas Gerais. The notion of prevention implies the dominant feeling of performing medical examinations from a symptom, against the idea of preventing, even when there is no clinical manifestation of the body.

The majority of students emphasize the advantages of early diagnosis and that the decisive factor for the cure corresponds to the moment of detection: "cancer must be discovered in time". This is a solid belief within the body of knowledge about the disease that can be used as a starting point in prevention messages.

However, even when the importance of early detection of cancer is understood as an essential element for its cure, care practices do not accompany the set of principles that regulate prevention or its demands.

\section{More Information}

*Address for Correspondence: Eduardo Blanco Cardoso, School of Education, University of São Paulo (USP), Brazil, Email: blancoec@uol.com.br; eblancocardoso@gmail.com

Submitted: February 19, 2020

Approved: December 30, 2021

Published: December 31, 2021

How to cite this article: Cardoso EB. Perception of Brazilian adolescents about cancer prevention. Clin J Nurs Care Pract. 2021; 5 : 055-059.

DOI: 10.29328/journal.cjncp.1001038

Copyright License: (๑ 2021 Cardoso EB. This is an open access article distributed under the Creative Commons Attribution License, which permits unrestricted use, distribution, and reproduction in any medium, provided the original work is properly cited.

Keywords: Social representations; Social interaction; Cancer; Adolescence

Check for updates

OPEN ACCESS

\section{Introduction}

Cancer is one of the leading causes of death and morbidity in Brazil [1]. Its mortality is related to characteristics of the disease's etiology and natural history, access and adherence to timely and quality treatments, as well as the incidence of different tumors in the population, according to its sociodemographic and clinical characteristics [2].

Given that certain changes in people's behavior may have a positive effect on reducing morbidity and mortality through the incorporation of healthy lifestyle habits, preventive practices, and the performance of screening tests, health policies should also be focused on promoting changes that encourage the development of behaviors in terms of early detection and timely treatment, as well as patient follow-up and rehabilitation [3].

In Latin America in general, and in Brazil in particular, beliefs about cancer are a relatively unexplored topic. Studies on the subject, and those involving knowledge about the most frequent cancers (breast, cervical, colorectal, prostate, lung, skin, etc.), with significant differences in terms of the number of published works, focus on analyzing the experiences of patients or people who have endured the disease, including family members or caregivers, and on the perspective of physicians and health professionals. Although they contain valuable knowledge for designing and implementing preventive and therapeutic interventions-both to modify "wrong" or "inaccurate" beliefs about the disease and to develop messages and communication strategies-studies that analyze the perception of cancer by healthy individuals, particularly adolescents, as well as their beliefs capable of influencing health behaviors, are scarce and relatively recent [4]. Ushering the "adolescent" onto the landscape of the disease, by studying the importance of prevention, is thus a true challenge. The identification of this concept will allow to establish an approach of how it is possible to influence protective behaviors and, at the same time, to help guide communication strategies in cancer control programs, adjusted to the cultural characteristics of the population. Although the disease is infrequent at this age, it is essential to promote proactive behaviors and attitudes towards health care, ranging from healthier lifestyles to an awareness of early detection programs, given that the absence of healthy habits is one of the main determinants of cancer in adult life. 


\section{Objective}

Investigate the concept of cancer prevention in primary and secondary school students enrolled in three public schools and one private school in the metropolitan region of São Paulo and the municipality of Dom Viçoso, Minas Gerais, Brazil.

\section{Methodology}

The sample comprised 980 students, aged between 12 and 18 years. The study utilized a self-administered, voluntary, and anonymous questionnaire composed of 10 open questions as a qualitative methodological strategy for data production, processing, and analysis. After a close reading of the responses, they were classified and grouped according to the criteria of the reference object to explore the following dimension: the concept of cancer prevention. This analytical procedure made it possible to identify how the prevention is experienced by the individuals in relation to the object in its different facets but also presents the participants' images, in terms of a positive or negative attitude towards the disease [5]. There was no measuring stick to indicate the quantity of the data needed to confirm the conclusions, which was thus subject to the researcher's judgment. The sample selection criteria randomly obeyed the responses provided, regardless of gender, age, and institutional origin. Student responses were identified by the number of participants expressed in parenthesis.

\section{Results and discussion}

\section{The concept of cancer prevention}

For most of the study participants, prevention is a positive term linked to life and health. It means "not getting sick," "treating oneself," "not dying," and "not losing vitality." Likewise, in a limited number of cases, there is an association between "prevention" and "avoidance," i.e., trying to prevent it from happening, doing what is necessary so that the disease does not appear.

To a certain extent, since all these positive actions would depend "on the individual's willpower," the "voluntarist" view of cancer ends up attributing responsibility for the disease to that individual specifically, within a certain ambiguity provided by the absence of clearly identified "causes." One possible explanation in this regard might be found in the socialization of the body in the cultural framework of a capitalist and patriarchal society such as that existing today. In this society, the individual is responsible for their fate, disconnecting them from their social origin and the inequality of opportunities, and educating them, whenever possible, in the biomedical alignment of "self-control." This contradicts the old but valid concept of Parsons [6] regarding illness as a "disturbance in the 'normal' functioning of the total human individual...it is thus partly biologically and party socially defined."
As a social expression, when students speak in their native Portuguese, they generally use verbs in the infinitive, which can be translated into English using the present participle, such as "going," "doing," "fighting," "receiving treatment," and "taking care of oneself," among others:

"...going to the doctor sooner" (no. 29); "fighting and receiving treatments" (no. 314); "taking care of yourself" (no. 113, no. 155); "to prevent it, you have to be informed" (no. 912, no. 432 , no. 868 ).

The concept of prevention thus comprises five areas or a body of knowledge and practices: going to the doctor, having medical tests and checks, receiving treatment, taking care of oneself, and finally receiving information. The first four practices involve subjective questions and individual values, and they require the health system to act as a producer of opportunities by organizing quality, accessible services that ensure the users are well received, as well as implementing preventive actions and messages. However, these requirements are not always available:

"...many people are unable to treat the disease and end up dying" (no. 567); "the person discovers it too late" (no. 693); "poor public health" (no. 509); "there isn't enough information on how to prevent it" (no. 948).

With regard to health demands, a study conducted by the polling institute Datafolha at the request of the Federal Council of Medicine (CFM, for its acronym in Portuguese) and the São Paulo Medical Association (APM, for its acronym in Portuguese), released on August 19, 2014, found that public and private health services in Brazil are bad, poor, or fair for $92 \%$ of Brazilians. There was also a feeling of dissatisfaction towards the Unified Health System (SUS, for its acronym in Portuguese) according to $87 \%$ of respondents. Delays in scheduling appointments, hospitalization, surgeries, and other specific procedures (chemotherapy, hemodialysis), as well as difficulty conducting laboratory and diagnostic tests, were some of the complaints.

This reality, to a certain extent, affects households and their members, who identify the health institution as "deficient." Although access to adequate, quality medical care is important, the unfathomable "social services" that permeate the community can delay consultations, with a consequent worsening of the prognosis.

The current health system, according to the roots and parameters that organize it in the modern era, does not fulfill the explicit social function assigned to it in democratic constitutions. In Brazil, as in different parts of the world, responsibility is not shared but rather assumed by the patient individually.

Although the culture of prevention should be taught in compulsory education, it is not; instead, it is acquired in 
non-formal processes that depend on the cultural level of the family and community in which the individual interacts. Unfortunately, working classes present the largest gaps [7]. If the intention is to remedy at least some of these disparities, it should be a public responsibility.

With regard to personal commitment, "taking care of oneself" alludes to issues associated with lifestyle and the adoption of habits considered healthy and protective:

"eating leafy and root vegetables and grains" (no. 9); "not smoking" (no. 239); "avoiding the use of toxic substances and contact with radiation" (no. 711); "using sunscreen..." (no. 751); "playing sports, eating well, not drinking alcohol" (no. 787); "having mammograms" (no. 217); "taking medication" (no. 102); "having surgery" (no. 67).

In the identification of risk factors defined by the biomedical model, some perceptions combine cognitive components with prescriptive ones; the population associates disease with behavioral practices, presumably those that are absent.

There is an identity established between "preventing" and "treating," where prevention expresses attention to health, interpreted as a "care" phenomenon, whether medical or surgical.

The prevalence of chronic diseases, especially cardiovascular (heart failure, heart attack), neurodegenerative (Alzheimer's, senile dementia), pulmonary (chronic bronchitis, emphysema), metabolic (diabetes, obesity), AIDS, and cancer itself, has increased dramatically in the Western world. This situation also implies a foreseeable increase in public spending, which is still low and insufficient in Brazil (8.1\% of the GDP in 2014, according to data from the Brazilian Institute of Geography and Statistics - IBGE, for its acronym in Portuguese), which places it at the tail-end of other more advanced countries, such as Germany and France, with investments close to $10 \%$ of the GDP.

A direct strategy to deal with both "spending" and the "disease burden" is to solve the problem at its origin through disease "prevention." Prevention and health promotion, through lifestyle changes, vaccines, and early detection can modulate the prevalence and severity of diseases, something that few other proposals are able to claim.

From another perspective, prevention can result in a concept that is easily assimilated by the population, less volatile, more intuitive, and politically correct: it is better to prevent diseases than to concentrate resources on treating them, as once they become clinically apparent, treatment may not be as effective.

Although it has its limitations, the "benefits" offered by prevention are certainly greater. Chronic diseases, which account for approximately $75 \%$ of health spending, are precipitated by risk factors that are often "modifiable" [8]. The relationship between the obesity epidemic and the incidence of diabetes is illustrative of this phenomenon. Risk factors such as "obesity" alone may influence the onset of diseases and the incurred expenses on a scale that few biomedical advances can match. Without going any further, four habits that are quite common in the US population (smoking, obesity, physical inactivity, and alcohol use) account for $38 \%$ of all deaths in that country [9]. In addition to the decrease in mortality due to lung, liver, and skin cancer-dependent on tobacco use, alcohol use, and sun exposure, respectivelyothers, such as breast and colorectal cancer, can also benefit from early detection in "screening programs", with reductions of up to $15-20 \%[10,11]$. Growing evidence indicates that over $50 \%$ of all cancers could be prevented if current knowledge of risk factors was successfully instilled in the population [12]. A study published recently in the journal Nature showed that up to $90 \%$ of cancers have their origins in external factors, i.e., they would not be the product of damaged DNA or simply bad luck, which reaffirms the need to commit more efforts to prevention than cure [13].

However, resistance to prevention and health promotion has different causes, ranging from simple skepticism about their usefulness and effectiveness to inertia, to the existence of powerful conflicts of interest or conflicting interests. Just remember, the commercial benefits derived from the business of "treating" are far superior to those of "preventing." In this context, poverty, associated with unemployment and inflation in labor income, causes disadvantaged people to lack preventive cultural filters, as well as the economic possibilities that would allow them to "minimize" or "correct" health problems. There is an invisible and symbolic barrierno less real or important-that excludes members of socially marginalized populations, preventing them from accessing prevention; their only option is the possibility of a "miracle" or the "treatment" of a biological and socially instilled disease.

In an important number of statements (29\%), it was found that "stress" and "anxiety," closely linked to a person's "psychological" and "emotional" aspects, are also included within the areas of preventive actions since they have the ability to modify bodies or impact their processes, sensations, and/or physiological functions. Thus, "avoiding" suffering and frustration is also seen as a form of prevention. Although none of these indications have scientific legitimacy, interesting studies began to emerge in the 1990s, used by some famous authors to question the relevance of "emotions" in health $[14,15]$.

Returning to the voluntarist conception of the disease, perceived as "something whose onset is allowed," there are sometimes explanations that disguise themselves with the rhetoric of "fate." This erroneous view sees illness as a one-off and inevitable event that is disconnected from any personal responsibility, including self-care. In the present study, some 
students dismissed cancer prevention or raised doubts about its effectiveness:

"there's no prophylaxis" (no. 820); "you can't avoid it" (no. 409, no. 421, no. 568, no. 601); "you can't avoid it, only mitigate it..." (no. 460); "there's no right way to avoid it" (no. 821); "there's no prevention for most cancers" (no. 899).

Not believing that cancer can generally be avoided by adopting preventive measures affords it representativeness and power that escapes any predictions. The human being is thus faced with a conflict: they are identified as being responsible for what happens to them, or as an actor moved by social forces greater than them, which victimize them uncontrollably.

The philosophical concept of personality as a set of potentialities, whose propensity towards specific goals can be intuited and supported by willpower, is betrayed and ignored in the hands of fate or bad luck. This attitude of denial can be one way to calm the anxiety and insecurity experienced by the individual, eliminating any sign of responsibility. However, it is also a result of the metaphorical ability of cancer as "an unexpected inner battle," which makes it in itself a phenomenon resistant to prediction and, consequently, prevention.

Knowledge and information are also configured as preventive spaces or areas; it is precisely these components that provide content for protective actions, guide behavior, and offer advice or answers: "we know if we're sick" (no. 604). They also make it possible to differentiate between what is good and bad and to recognize what is not related to either of them:

"Prevention involves playing sports, eating well, not drinking alcohol" (no. 416); "having campaigns that bring knowledge to everyone" (no. 222); "it's good to learn new things" (no. 231); "...informing students at school so that they talk about it with their relatives" (no. 125).

Different studies and investigations carried out in Brazil have considered the normative characteristics of health care and prevention for the population $[16,17]$. Prevention is thus also to some extent conceived as "heeding professional advice." Surely, in the traditionalist social view, the figure of the doctor-after the priest-is the one that stands out most. In effect, the doctor and priest are directly and indirectly responsible for a supreme good: life. With regard to the former it is, therefore, logical to consider that he has sufficient authority to treat the patient and their illness on the earthly plane. This condition is recognized by the patient and strengthened by basic qualities attributed to him: possessing the technical knowledge, abilities, and skills that ensure "good results" and "obedience" to his advice.

These attributes are based on the concept that both the doctor and patient-scholar and layperson-should have certain roles. The doctor's role is to be useful to the patient, while the patient accepts what the doctor advises, since, as a layperson, they do not have sufficient tools to ensure their diagnosis and treatment. In turn, it is necessary for the individual to assume the role of the patient, so that the doctor can legitimately take charge of their "problem" as an expert. The doctor-patient relationship is thus recognized as an integral part of the social system that rests on an order of interactions with well-established roles and functions.

In this reasoning, human reactions in response to stimuli, such as cancer prevention, are related to certain definitions or behaviors, which are common to all members of the community to which they belong. Going to the doctor is part of this "commitment" in many cultures.

Although it is not the object of analysis, it should be mentioned that the preventive inertia adopted by many health system users may be due to a number of reasons, some of which are related to employment (lack of time, operation hours of the health care service, etc.), the precarity of public services (lines, long waiting times, delays in scheduling tests and consultations, lack of professionals, etc.), economic difficulties (less purchasing power, unemployment, transportation, etc.), a lack of information (campaigns, task forces), personal issues (lack of symptoms, bodily exposure, embarrassment, physical discomfort, fear of discovering a serious illness), and skepticism itself [18-20]. In these circumstances, the individual confronts a series of events, which constitute an obstacle aimed at a preconceived goal: "taking care of oneself." The inferences pointed out denounce the presence of both structural and organizational constraints in health, which make it difficult to adopt self-care practices.

Until only recently, Brazil was experiencing an apparent state of health prosperity, in which socioeconomic inequalities had a minimal impact on patient survival. Unfortunately, the economic crisis that has plagued the world over the last nine years (public debt, weak financial institutions, economic slowdown, etc.) has created the unfortunate situationwhich has not yet been remedied-that only "affluent" patients will survive or have a better quality of life over the course of their illness. This chaotic scenario creates an environment that is conducive for cancer to become the great "ghost of the twenty-first century"; as a ghost, it will be able to pass more unnoticed than wars and terrorism, giving itsocially—an even more "dangerous" and "lethal" appearance than it has achieved thus far.

\section{Conclusion}

The notion of prevention entails the dominant sense of carrying out controls based on "symptoms", disrespecting the idea of preventing even when there is no corporal manifestation. In this context, prevention and treatment are usually identified as synonyms. 
There is consensus about the advantages of early diagnosis and that the decisive factor is the moment of detection: "cancer must be discovered in time". This is a solid belief within the set of knowledge about cancer that can be used as an anchor point for prevention messages.

However, even when the importance of early detection of the disease as an essential element for the cure of cancer is understood, care practices do not accompany the norms of prevention nor their demands.

Confidence in science, an optimistic attitude towards medical advice, and the legitimizing value granted to the best time to identify cancer-a determining factor for its cure-among other ideas can be a platform to deconstruct old convictions and conceive new ones to give real meaning to preventive behaviors.

\section{Acknowledgment}

Many thanks to Professor Fernando Gil Villa, whose book "La cara social del cáncer" was a source of inspiration for this project.

\section{References}

1. Ministry of Health. 2015. Health Surveillance Secretariat. Department of surveillance of non-communicable diseases and conditions and health promotion. Saúde Brasil 2014: An analysis of the health situation and external causes/Ministry of Health, Health Surveillance Secretariat, Department of Non-Communicable Disease and Health Surveillance and Health Promotion. Brasília, Brazil: Ministry of Health

2. Goss PE, Lee BL, Badovinac-Crnjevic T, Strasser-Weippl K, ChavarriGuerra $Y$, et al. Planning cancer control in Latin America and the Caribbean. Lancet Oncol. 2013; 14: 391-436.

PubMed: https://pubmed.ncbi.nlm.nih.gov/23628188/

3. National Cancer Institute. Cancer screening overview (PDQ®)-health professional version. 2017. https://www.cancer.gov/about-cancer/ screening/hp-screening-overview-pdq

4. Blanco EC, Schilling F. Percepções sobre o câncer na visão de pacientes, familiares e equipe de saúde. In Anais da $12^{\circ}$ conferência internacional sobre representações sociais e IV colóquio LusoBrasileiro sobre saúde, educação e representações sociais. 2004; 2529-2536.

5. Bardin L. Análise de conteúdo. Lisboa, Portugal: Edições 70 Ltda. 2002.

6. Parsons T. El sistema social. Madrid, Spain: Ed. Alianza Universidad. 1982.
7. Villa FG. La cara social del cáncer. Barcelona, Spain: Ediciones Octaedro, S.L. 2012

8. Woolf SH. The power of prevention and what it requires. JAMA. 2008; 299: 2437-2439.

PubMed: https://pubmed.ncbi.nlm.nih.gov/18505953/

9. Woolf $\mathrm{SH}$. The big answer: Rediscovering prevention at a time of crisis in health care. Harvard Health Policy Review. 2006; 7: 5-20.

10. http://www.sehn.org/tccpdf/the/big/answer.pdf

11. Nelson HD, Tyne K, Naik A, Bougatsos C, Chan BK, et al. Screening for breast cancer: An update for the U.S. preventive services task force. Ann Inter Med. 2009; 151: 727-737.

12. Vecchia C. Fecal occult blood screening for colorectal cancer: Open issues. Ann Oncol. 2002; 13: 31-34.

PubMed: https://pubmed.ncbi.nlm.nih.gov/11863106/

13. Colditz GA, DeJong W, Emmons K, Hunter DJ, Mueller N, et al. Harvard Report on Cancer Prevention. Vol 2: Prevention of Human Cancer. Cancer Causes Control. 1997; 8: S1-S3.

14. Wu S, Powers S, Zhu W, Yusuf A. Hannun. 2016. Substantial contribution of extrinsic risk factors to cancer development. Nature. 529: 43-47.

PubMed: https://pubmed.ncbi.nlm.nih.gov/26675728/

15. Goleman D. Inteligência emocional. Rio de Janeiro, Brazil: Objetiva. 2013.

16. Lillberg K, Verkasalo PK, Kaprio J, Teppo L, Helenius H, et al. Stress of daily activities and risk of breast cancer: A prospective cohort study in Finland. Int J Cancer. 2001; 91: 888-893.

PubMed: https://pubmed.ncbi.nlm.nih.gov/11275996/

17. Carvalho AD, Kose LM. AIDS: Ainda dá tempo de se prevenir. III COMSAÚDE - comunicação e promoção da saúde. Adamantina, São Paulo: Comtexto Comunicação e Pesquisa S/C Ltda. 2000.

18. de Araujo IS, Cardoso JM. Comunicação e saúde. Rio de Janeiro, Brazil: Fiocruz. 2007.

19. Hardy E, Jiménez AL. Masculinidad y género. In Salud y equidad: Una mirada desde las ciencias sociales, eds. Briceño-León $R$, de Souza Minayo MC, Carlos EA. Coimbra, 349-359. Rio de Janeiro, Brazil: Editora Fiocruz. 2002.

20. Gomes R, Nascimento EF, Araujo FC. Por que os homens buscam menos os serviços de saúde do que as mulheres? As explicações de homens com baixa escolaridade e homens com ensino superior. Cadernos de Saúde Pública. 2007; 23: 565-574.

21. Schraiber LB. Equidade de gênero e saúde: O cotidiano das práticas no programa saúde da família do recife. In Gênero e saúde: Programa saúde da família em questão, eds. Wilza Villela, and Simone Monteiro, 39-61. Rio de Janeiro, Brazil: Abrasco, Fundo de População das Nações Unidas. 2005. 